\title{
ESBOÇOS
}

Revista do Programa de Pós-Graduação em História da UFSC

\section{Dossiê: AMÉRICA LATINA}

$2008 / 2$ 
Pede-se permuta

Pédese canje On demande échange We ask for exchange Wir bitten um austausch Se richiedle lo scambio 
ESBOÇOS - Revista do Programa de Pós-Graduação em História da UFSC.

No 20, Florianópolis, 2008/2. Semestral. ISSN |4|4-722x

\section{Coordenadora do Programa de Pós-Graduação em História da UFSC}

Maria Bernardete Ramos Flores

\section{Conselho Editorial}

Adriano Luiz Duarte

Ana Lice Brancher

Henrique Espada Rodrigues Lima Filho

Marcos Fábio Freyre Montysuma

Maria de Fátima Fontes Piazza

Renata Palandri Sigolo

\section{Conselho Consultivo}

Antônio Luigi Negro (UFBA); Barbara Weinstein (NYU); Benito Bisso Schmidt (UFRGS); Christina da Silva Roquetti Lopreato (UFU); Cláudio Bertolli filho (UNESP); Cléria Botelho da Costa (UnB); Edgar Salvadori de Decca (UNICAMP); Élio Cantalício Serpa (UFG); Fernando Teixeira da Silva (Unicamp); Gilmar Arruda (UEL); Horacio Gutiérrez (USP); Iara Lis Franco S. C. de Souza (UNICAMP); Ítalo Arnaldo Tronca (UNICAMP); Izabel Andrade Marson (UNICAMP); Jaime Yaffe (Universidade de la República - Uruguay); Luciene Lemkhul (UFU); Mirta Lobato (UBA - Argentina); Maria Tereza Santos Cunha (UDESC); Márcia Regina Capelari Naxara (UNESP - Franca); Ricardo Muller (Sociologia - UFSC); Rosângela Miranda Cherem (UDESC); Sidnei Munhoz (UEM); Valdir Gregory (UNIOESTE); Vavy Pacheco Borges (UNICAMP).

Organizadoras desse número: Maria Bernardete Ramos Flores e Ana Lice Brancher

\section{Universidade Federal de Santa Catarina - UFSC}

Programa de Pós-Graduação em História

Campus Universitário - Trindade

Cep: 88040-900 - Florianópolis-SC

e-mail: esbocos@cfh.ufsc.br

Fone/fax: (48) 37219359

http://www.periodicos.ufsc.br/index.php/esbocos/

Revisão Geral: Ana Lice Brancher

Editoração: Nova Letra Gráfica e Editora

Capa: Ana Brancher sobre a tela "Raízes" (1943) de Frida Kahlo (1907 - 1954).

Tiragem desta edição: 500

Publicação sem fins lucrativos dirigida aos profissionais e estudantes de História. Tem como objetivos incentivar a publicação de pesquisas e disponibilizar novas temáticas e fontes aos pesquisadores.

O conteúdo e a metodologia empregados nos artigos são de inteira responsabilidade dos autores. 


\title{
PROGRAMA DE PÓS-GRADUAÇÃO EM HISTÓRIA - UFSC HISTÓRIA CULTURAL
}

\section{LINHAS DE PESQUISA E O CORPO DOCENTE:}

\author{
1. POLÍTICAS DA ESCRITA, DA IMAGEM E DA MEMÓRIA \\ Dra. Ana Lice Brancher \\ $\mathrm{Dr}^{\mathrm{a}}$. Maria Bernardete Ramos \\ $\mathrm{Dr}^{\mathrm{a}}$. Maria de Fátima Fontes Piazza \\ Dr. Mário César Coelho \\ Dr. Waldir José Rampinelli
}

\section{MIGRAÇÕES, CONSTRUÇÕES SÓCIO-CULTURAIS E MEIO AMBIENTE \\ $\mathrm{Dr}^{\mathrm{a}}$. Ana Lúcia Vulfe Nötzold \\ $\mathrm{Dr}^{\mathrm{a}}$. Eunice Sueli Nodari \\ Dr. João Klug \\ Dr. Marcos Fábio Freyre Montysuma}

\section{RELAÇÕES DE PODER E SUBJETIVIDADES}

Dr. Artur Cesar Isaia

Dr. Cristina Scheibe Wolff

Dra. Cynthia Machado Campos

Dra. Joana Maria Pedro

Dr. Rogério Luiz de Sousa

Dra. Roselane Neckel

Dr. Valmir Francisco Muraro

\author{
4. TRABALHO, SOCIEDADE E CULTURA \\ Dr. Adriano Luiz Duarte \\ $\mathrm{Dr}^{\mathrm{a}}$. Beatriz Gallotti Mamigonian \\ Dr. Henrique Espada Rodrigues Lima Filho \\ Dr. Paulo Pinheiro Machado \\ $\mathrm{Dr}^{\mathrm{a}}$. Renata Palandri Sigolo
}




\section{SUMÁRIO}

APRESENTAÇÃO

\section{ARTIGOS}

Cabeças Cortadas da Mesoamérica

Sérgio Medeiros

Representações populares e de elite na Argentina e no Brasil do Entre-Guerras a partir de Carlos Gardel e Carmen Miranda

Alessander Mario Kerber e Claudia Wasserman

O ano de 1968 em Cuba: Mudanças na política internacional e na política cultural

Silvia Cezar Miskulin

Las políticas de Seguridad y Defensa en Paraguay: perspectivas y desafíos frente al nuevo escenario político

Sonia Winer

El Movimiento 'Cocalero' en Bolivia durante los años 80 y 90: sus causas y su su desarrollo

Šárka Malá

'Realidades': O Brasil que se constrói sob o olhar da Venezuela, TeleSur TV

Antônio M. Elíbio Júnior e Beatrice C. O. Gonçalves.

Exaltação do mestiço: A invenção do roto chileno

Horacio Gutiérrez

A palheta e o pincel na construção de um mito fundador

Susana Bleil de Souza

Carlota Palmerola - Kuña Paraguay

Margarita Durán Estragó

A formação da nação e o vazio na narrativa argentina: ficção e civilização no século XIX

José Alves de Freitas Neto

Políticas na exterioridade - notas sobre o exílio de escritores latinoamericanos

Ana Brancher e Fábio Francisco Feltrin de Souza. 205 
Expandiendo paradigmas, rediseñando fronteras: La diplomacia cultural norteamericana y la búsqueda de una comunidad interamericana de académicos

Claudio González-Chiaramonte

A influência francesa dentro do Exército brasileiro (1930 - 1964): declínio ou permanência?

Rodrigo Nabuco de Araujo

A política internacional de JK e suas relações perigosas com o Colonialismo português

Waldir José Rampinelli

\section{RESENHAS}

Cenas, corpos e clausuras uruguaias

Gabriel Felipe Jacomel

Questionamentos sobre gênero, família e trabalho na América Latina

Soraia Carolina de Mello 299

Tempo passado: cultura da memória e guinada subjetiva: um contraponto ao boom da memória nos estudos históricos

Fernando C. Boppré

A teoria e a prática dos intelectuais no passado e no presente

Diogo da Silva Roiz

NORMAS PARA PUBLICAÇÃO 


\section{APRESENTAÇÃO}

No dia 15 de fevereiro de 1857, El Correo de Ultramar, periódico literário editado em Paris ${ }^{1}$, publicava o poema Las dos Americas do poeta, escritor e diplomata colombiano José Maria Torres Caicedo $(1830$ - 1889). O veemente poema, composto de $\mathrm{X}$ cantos, 36 estrofes e 318 versos, expressa o panorama político das Américas de meados do século XIX: o fortalecimento dos Estados Unidos da América como nação autônoma e poderosa e a necessidade dos recémindependentes países ao Sul do continente de unir-se para fazer frente ao vizinho "lleno de ambición" e à Europa onde "domina el despotismo". No transcorrer do poema, referindo-se aos Estados Unidos o poeta diz "la sajona raza" e para referir-se aos países do Sul, o poeta inova. Prestemos atenção ao quinto verso do canto IX:

Mas aislados se encuentran, desunidos,
Esos pueblos nacidos para aliarse:
La unión es su deber, su ley amarse:
Igual origen tienen y misión;
La raza de la América latina,
Al frente tiene la sajona raza,
Enemiga mortal que ya amenaza
Su libertad destruir y su pendón.

Segundo analistas, esta foi uma das primeiras vezes que se utilizou a expressão América Latina. A diplomacia francesa passou a adotar essa denominação para designar o que então se chamava América Portuguesa e Espanhola, para desenvolver a sua política panlatinista e em contraposição aos interesses do mundo anglosaxão. A partir de então, a expressão e a idéia de América Latina ${ }^{3}$ começam a ser difundidas e instrumentalizadas como projeto político; convém ressaltar, todavia, que a necessidade de união dos países sulamericanos/latinoamericanos se anunciava já em fins do século XVIII ganhando forças ao longo do século XIX. O poema de Torres Caicedo evidencia uma das muitas faces das interseções da história com a literatura, neste caso com a poesia.

Desde suas independências, aproximadamente entre 1810 e 1830 , o que se convencionou chamar de América Latina passou por acentuadas transformações no panorama político e cultural, com a consolidação dos Estados Nacionais, com revoluções paradigmáticas como a Revolução Mexicana e a Cubana, com governos que marcaram indelevelmente a memória coletiva do continente (peronismo, 
varguismo e cardenismo), os golpes de Estado civis/militares e a resistência armada, além de importantes movimentos de vanguarda (com revistas, manifestos e obras literárias em prosa e verso, cinema, artes visuais, música) que integraram a unidade/diversidade da região ${ }^{4}$.

Com o intuito de somar-se às comemorações do bicentenário da independência dos países latinoamericanos, a Esboços - Revista do Programa de Pós-Graduação em História, publica o presente dossiê. Os autores - pesquisadores ligados à Universidades brasileiras e à Universidades do Paraguay, Argentina, Estados Unidos, República Tcheca e França - lançaram mão das artes visuais, das relações internacionais, da literatura, das relações de gênero, dos movimentos sociais, das conexões culturais, para questionar sob diferentes linhas téoricas, a história de Nuestra América. Completam o volume, quatro resenhas que refletem sobre as discussões no âmbito da renovação das práticas historiográficas. Como uma colaboração especial à Esboços, contamos com o ensaio de Sérgio Medeiros, tradutor para o português do Popol Vuh, o livro dos "vários começos e que, por isso, é o livro dos começos, ou dos devires numerosos".

Esperamos contribuir para a divulgação das pesquisas sobre a história do continente e adiantamos ao leitor, a partir do ensaio que abre este volume, o prazer de alcançar os versos,

$X$ u riq nabe ' $u$ bi,

Xa q'u zkakin chik $x$ ch'atah vi.

Xere ma vi $x$ u biih chik

U bi ri, u hunal puvil u chi,

Xere pu $x$ ch'atah chi vi.

Ana Brancher

Maria de Fátima Fontes Piazza

Organizadoras

\section{NOTAS}

I O jornal/revista literária foi editado entre 1842 e I886. Segundo estudo de Catherine Sablonniere, a linha editorial adotava uma postura conservadora mas que destoava de alguns dos artigos nele publicados; circulou nas Américas e na Europa e chama a atenção o longo período de duração do jornal para a época, o que carateriza um fiel público leitor e um suporte financeiro razoável. Cf. SABLONNIERE, C. "EI Correo de Ultramar (I 842- I 866) y la ciencia: entre la labor educativa y la propaganda política" in

http:/historiadoresdelaprensa.com.mx/hdp/files/272.pdf

2 A íntegra do poema está disponível em: http://nww.filosofia.org/hem/I85/I85702। 5.htm

3 Também como contraposição a América anglosaxona Cf. PHELAN, J. "El origen de la idea de Latinoamérica" in ZEA, L. (comp.) Fuentes de la cultura Latinoamericana. v. I. México: Fondo de Cultura Económico, 1995.

4 Cf. SCHWARTZ, J. Vanguardas latino-americanas: polêmicas, manifestos e textos críticos. São Paulo: EdUSP, 2008. 